\title{
The Opportunities and Dilemmas of the Transformation of Traditional Agricultural Towns into Modernized Agriculture - Based on the Experience of Shilong Town
}

\author{
Yaping Jiang ${ }^{1}$ Binyu $\mathrm{Hu}^{1, *}$ \\ ${ }^{1}$ College of Commerce, Chengdu University, Chengdu, Sichuan 610000, China \\ *Corresponding author. Email: 15828430146@163.com
}

\begin{abstract}
Since the reform and opening up, Chinese grain has grown continuously and agricultural construction has made great achievements. However, with Chinese economic development and industrial structure upgrading and transformation, the traditional agricultural development model has been unable to keep up with the needs of social development, so there is an urgent need for development to adapt to modern productivity. Traditional agricultural towns have inherent advantages but also face huge challenges to achieve agricultural transformation. This article collects information through interviews, and analyzes and summarizes the problems encountered in the transformation of Shilong Town, where traditional agriculture is the leading industry, in the process of transforming into a new type of agriculture. In response to these problems, solutions were proposed to provide the "stone dragon experience" for the transformation of traditional agricultural towns in Sichuan.
\end{abstract}

Keywords: Modern agriculture, Opportunities, Challenges.

\section{INTRODUCTION}

Chinese modern agriculture has been developed for more than 30 years, and it has accumulated certain experience and achieved certain achievements in the development of rural modern agriculture. At present, China is accelerating the pace of rural revitalization. Agricultural modernization is an important part of rural revitalization. It can be said that the construction of agricultural modernization in traditional agricultural towns will push the rural revitalization strategy forward a big step. However, we must also realize that traditional agricultural towns also have many problems in the process of developing modern agriculture due to factors such as geographic location, economic status, and demographic structure. Unless these problems faced by traditional agricultural towns are solved, agricultural transformation cannot be truly achieved. If achieved, rural development cannot be achieved. Therefore, how to formulate a prescription to solve the problem of the transformation of traditional agricultural towns is a problem that must be solved at present. This article takes Shilong Town, Liangshan Prefecture as an example, discusses the difficulties faced by traditional agricultural towns in the process of developing modern agriculture, and proposes solutions to the difficulties, which can provide references for the modernization of other similar traditional agricultural towns.

\section{RESEARCH METHODS}

This study uses comparative analysis, literature analysis, and field investigation methods to analyze the current situation of the development of modern agriculture in Shilong Town, Liangshan Prefecture and the problems encountered in the development process, and study the countermeasures to solve the plight of the development of modern agriculture in traditional agricultural towns in China. 


\section{CONCEPTS AND CHARACTERISTICS OF MODERN AGRICULTURE}

\subsection{The Concept of Modern Agriculture}

Modern agriculture is a new form of agriculture developed on the basis of primitive agriculture and traditional agriculture. The basis of modern agriculture is social progress and technological progress. After the new development concept of "innovation, coordination, green, openness and sharing" was put forward, Chinese modern agriculture has been endowed with new connotations. We pursue a modern agricultural production method in China based on the principles of ecological economy and green development as the goal. Modern agriculture has become an effective way to achieve sustainable agricultural development in my country and speed up the construction of beautiful rural areas, as well as an important means to upgrade traditional agriculture in my country to achieve high-quality rural development.

\subsection{Characteristics of Modern Agriculture}

The development of traditional Chinese agriculture from a farming society to today is showing new characteristics and new problems. Under the joint promotion of capital, market, and industry, on the one hand, China's traditional agriculture is rapidly being replaced by modern agriculture. On the other hand, traditional agricultural towns have exposed some new problems due to the characteristics of modern agriculture in the process of agricultural upgrading.

\subsubsection{Sustainable Agriculture}

In order to avoid the negative impact of industrial modernization on human development, and to take into account future food security, human development, environmental protection and other issues, modern agriculture is a sustainable agricultural production model. On the one hand, modern agriculture pursues the convenience of agricultural development brought by industrial clusters and pursues economic benefits. On the other hand, modern agriculture also pursues the sustainability of development and the pursuit of social benefits.

\subsubsection{High-quality Agriculture}

Modern agriculture is a technology-intensive and capital-intensive agricultural production method. Modern agriculture is the agriculture with product quality as the lifeline, the agriculture that realizes the specialization of the agricultural production structure, the agriculture with the goal of high economic returns, and the open agriculture promoted by technological innovation and management innovation. Modern high-quality agriculture ensures the whole process of quality assurance "from field to table".

\section{THE STATUS QUO OF MODERN AGRICULTURAL DEVELOPMENT IN SHILONG TOWN}

Shilong Town is located in Mianning, Sichuan. The agriculture is mainly planted with rice, barley, and corn. At the same time, the development of flue-cured tobacco, vegetables and sericulture, the sericulture breeding has become large-scale, and the establishment of sericulture breeding cooperatives. The animal husbandry is dominated by pig breeding. It is a pollution-free pig production base in Sichuan Province. A large-scale pig breeding base has been built in the town. The town has 1 junior high school, 5 village primary schools, and 1 health center.

At present, Shilong Town is vigorously developing new types of planting and breeding, building more than 1,000 acres of vegetable and fruit greenhouses, and dozens of new-type family farms. Compared with traditional agriculture, Shilong Town has carried out a new round of land reform through land rectification and land transfer in recent years. In the past, the land of each household was relatively scattered, and management was difficult. The harvest of the crops depended on the weather. Nowadays, cooperatives have been built through land contracting, and new types of fruit and vegetable cultivation have also moved into large sheds, and the output and value of vegetables and fruits have been increased. Through field surveys and visits, we also found that in the process of modern agricultural construction, the farmers in Shilong Town are also facing great pressure. 


\section{CHALLENGES IN THE DEVELOPMENT OF MODERN AGRICULTURE IN SHILONG TOWN}

\subsection{The Lack of Government Management Functions}

During the interview, it was discovered that the local farmers are mainly engaged in production and operation in a spontaneous manner. In the inquiry to the local cooperative, it was found that the cooperative was established on the basis of relatives. The government's participation in the establishment and operation of the entire cooperative, production and sales of products is relatively small, or even lack of government guidance, which has left a lot of hidden dangers in the modernization of local agriculture.

\subsection{Backward Rural Infrastructure}

The investigation found that there is a lack of large-scale trading markets in the area. At present, the only trading market has inconvenient transportation and imperfect management. The lack of good market transactions makes the local agricultural and sideline product transactions not high. Local residents can only ship the products to other township markets, which increases the overall cost of products and reduces profits.

\subsection{Large Constraints on Agricultural Financing}

The current planting is mainly divided into three forms: cooperatives, large-scale contracting, and individual contracting. Cooperatives and large households account for $80 \%$ of all planting. Although the scale of cooperatives and large households is large, the survey found that the first two years of greenhouse planting require continuous capital investment without return, and it is difficult for farmers to spontaneous family-style planting and breeding without third-party guarantees. Meanwhile, the small scale of individual planting makes it more difficult to obtain loans and even more difficult to manage.

\subsection{Single Industry Development}

By investigating the industrial structure of the area, it is found that the local industry is dominated by the primary industry, the secondary industry has just started, and the tertiary industry is almost nonexistent.

\section{SUGGESTIONS FOR THE FUTURE DEVELOPMENT OF MODERN AGRICULTURE IN SHILONG TOWN}

\subsection{The Government Strengthens Guidance and Improves Supporting Policies}

The local government should strengthen guidance and help villagers establish cooperatives to carry out larger-scale agricultural production. Only in this way will it be conducive to the formation of a new round of economies of scale in rural areas and help farmers increase production and income. At the same time, the government urgently needs to improve the supporting policies for agricultural development, strengthen infrastructure construction, and provide greater policy support and economic subsidies to help growers and farmers to establish a more scientific management team, so that the rural primary industry can continue to develop healthily.

\subsection{Guiding Industrial and Commercial Capital to Invest in Agriculture}

For agriculture to develop, the funding problem must be resolved. Farmers' low risk-bearing capacity and lack of third-party credit guarantees make it difficult to finance agricultural development. To resolve the difficulty of agricultural financing constraints, the government should first introduce some loan policies to guide banks and credit cooperatives to lend to farmers; second, the government can conduct certain investment promotion activities to guide foreign capital to invest. But at the same time, the government should also pay attention to the risks brought by the influx of industrial and commercial capital, and prevent the disorderly entry of capital from bringing huge financial risks to farmers.

\subsection{Development of Diversified Industries}

Only by taking the road of diversified development can agricultural modernization go further. A single industry often cannot withstand the test of the market. Once the market is slightly turbulent, it may cause a devastating blow to the local economy. In the context of the current 
industrial structure upgrade, agriculture should also follow closely and derive industrial chains. Shilong Town should develop agricultural and sideline product processing, agricultural leisure tourism and other related industries based on planting and breeding, take multiple strategies to build a characteristic industrial chain, create a new development model of integrated operation and socialized services, and explore new situations A new model for the development of traditional agricultural towns.

\section{CONCLUSION}

In China, agriculture has played a very important role in Chinese economic development. For a long time, agriculture has served other industries, but with the country's rural revitalization strategy, rural agricultural development has once again occupied the spotlight on the stage. How to develop Chinese agriculture in the context of economic transformation and industrial restructuring? This is a big article that needs to be written by the whole society. The development of the country cannot be separated from the revitalization of agriculture, and the people's livelihood cannot be separated from the development of agriculture. The development of traditional agriculture to this day requires a modern transformation. Modern agriculture is an important part of Chinese rural revitalization and a new engine for Chinese rural economic growth.

\section{AUTHORS' CONTRIBUTIONS}

Yaping Jiang organized research work. He is responsible for collating survey data and writing papers. Binyu Hu participated in field research and she was in charge of writing records during the field investigation.

\section{REFERENCES}

[1] Gao Jianjun, Zhang Tongguang. Financial support for new agricultural business entities under the background of rural revitalization strategy - Comment on "Financial support for new agricultural business entities under the background of rural revitalization strategy" [J]. Plant Quarantine, 2021, 35(02): 92. "In Chinese"

[2] Yu Chang, Cong Jing, Peng Hongjun. The development of characteristic agriculture: the status quo, problems and development countermeasures - Taking Sancang Town, Dongtai City as an example [J]. China Forestry Economics, 2021(02): 22-25. "In Chinese"

[3] Li Shuqian, Xie Xiaoyue. Research on financial support for new agricultural management entities under the perspective of rural revitalization: Taking Shanxi Province as an example [J]. Shanxi Agricultural Economics, 2021(04): 7-9."In Chinese"

[4] Sun Ying. The development of modern agriculture should highlight the leading role of new agricultural management entities [J]. Contemporary Agricultural Machinery, 2021(02): 13-14."In Chinese"

[5] Liu Yangde. The path of financial support for new agricultural business entities. Taking Sichuan Weiyuan Rural Commercial Bank as an example [J]. Contemporary County Economy, 2021(02): 90-93. "In Chinese"

[6] Huang Zuhui, Yu Ning. The main body of new agricultural management: status quo, constraints and development ideas-an analysis based on Zhejiang Province [J]. China Rural Economy, 2010(10): 16-26+56. "In Chinese" 